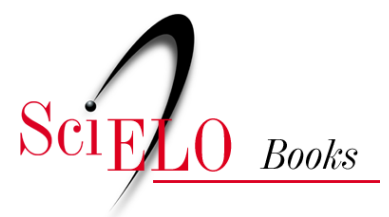

\title{
4. Condição racial e o grupo dos ricos
}

\author{
Emerson Ferreira Rocha
}

\section{SciELO Books / SciELO Livros / SciELO Libros}

ROCHA, E.F. Condição racial e o grupo dos ricos. In: O negro no mundo dos ricos: um estudo sobre a disparidade racial de riqueza com os dados do Censo 2010 [online]. Brasília: Editora UnB, 2019, pp. 91-110. Pesquisa, inovação \& ousadia series. ISBN: 978-65-5846-052-7. https://doi.org/10.7476/9786558460527.0006.

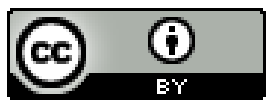

All the contents of this work, except where otherwise noted, is licensed under a Creative Commons Attribution 4.0 International license.

Todo o conteúdo deste trabalho, exceto quando houver ressalva, é publicado sob a licença Creative Commons Atribição 4.0.

Todo el contenido de esta obra, excepto donde se indique lo contrario, está bajo licencia de la licencia Creative Commons Reconocimento 4.0. 


\section{Condição racial e o grupo dos ricos}

Como foi visto no capítulo anterior, obedecendo a lógica subjacente da acomodação das relações raciais em posições de classe, a desigualdade racial atinge um estado crítico nas posições mais elevadas da distribuição de renda. Foi visto que, especialmente no percentil que delimita o grupo dos ricos conforme aqui definido, é maior a magnitude da desigualdade de renda associada ao indicador de condição racial. Contudo, antes de avançar ao estudo dos determinantes da riqueza, tarefa do próximo capítulo, é importante observar como a desigualdade racial de renda, especialmente a desigualdade racial na composição do grupo dos ricos, se relaciona à desigualdade de renda em geral. Uma pergunta muito importante a se fazer é: a redução da disparidade racial de riqueza reduziria a desigualdade de renda na população total?

Além disso, considere-se que a desigualdade racial de riqueza pode ser considerada sob dois aspectos. Um referente à composição do grupo dos ricos e outro referente aos níveis de riqueza dos ricos ou, em outras palavras, ao quanto os ricos são ricos. Como o grupo dos ricos é definido em termos de uma linha de rendimentos, é de se esperar alguma homogeneidade de renda entre negros e brancos dentro desse grupo. Trata-se, afinal, do conjunto de negros e de brancos com rendimentos acima da linha da riqueza. Se os negros são minoria nesse grupo, não é necessário que, além disso, dentro desse grupo eles tenham níveis de afluência inferiores aos dos brancos. A disparidade 
racial de riqueza poderia ser apenas de composição. Nesse capítulo, testa-se também a hipótese de que existe disparidade racial de riqueza em termos de nível.

\subsection{Os métodos utilizados}

Embora a noção de distribuição de rendimentos seja intuitivamente evidente, cabe explicitar as características básicas que a definem. Uma delas é o "nível” da distribuição, ou seja, a magnitude das quantidades distribuídas. A outra é a "forma” da distribuição, ou seja, a configuração assumida pela dispersão dessas quantidades. Descrever uma distribuição de rendimentos significa, essencialmente, oferecer uma representação adequada para essas duas características. Para realizar essa tarefa, existem diferentes recursos disponíveis. A principal preocupação ao se escolher qualquer um deles diz respeito às informações que eles mantêm ou perdem. Essa questão é especialmente sensível no que se refere à ‘forma’ da distribuição. Medidas como o Coeficiente de Gini, por exemplo, são meios para representar características da forma de uma distribuição. Trata-se de definir uma função que "traduzirá" toda uma curva em termos de um único número. Mais do que nunca, traduzir é trair. Certamente há perdas de informação no processo. Nesse sentido, tabelas e gráficos assumem um interesse especial. Principalmente os gráficos que, enquanto representações espaciais, fazem um bom trabalho em preservar informações sobre a forma da distribuição, oferecendo, além disso, uma abordagem bastante intuitiva.

Por outro lado, medidas sintéticas possuem suas próprias vantagens. A primeira, e mais óbvia, refere-se exatamente ao seu poder de síntese. Há uma simples questão de economia na exposição. É simplesmente conveniente poder expressar um conjunto grande de informações em um conjunto mais enxuto. O mais importante, contudo, é que medidas sintéticas possuem algumas vantagens do ponto de vista analítico. Por elas serem obtidas através de determinadas funções, é possível definir funções de modo a priorizar certo tipo de informação. Por exemplo, uma medida sintética de riqueza pode ser definida para representar a proporção dos ricos na 
população total. Modificando sua função, pode-se obter uma medida que também preserve informações sobre a desigualdade de renda entre os ricos.

Outra vantagem analítica das medidas sintéticas é a possibilidade decompôlas. Tais medidas podem ser decompostas em fatores ou subgrupos que compõem a distribuição total dos rendimentos. Se for esse o interesse, uma medida de desigualdade de renda pode ser decomposta com base na contribuição de diferentes fontes de rendimento: trabalho, pensões, aluguéis, etc. Já no presente caso, deseja-se decompor medidas em subgrupos: negros e brancos. Nem todas as medidas são igualmente decomponíveis. Essa característica depende da função matemática que a define. No presente estudo, opta-se por trabalhar com a medida de desigualdade dada pelo Índice de Theil (1979), já que essa permite a decomposição aditiva da desigualdade total, que, no nosso caso, passa a ser dada por três componentes: a desigualdade interna ao grupo dos negros, a desigualdade interna ao grupo dos brancos e a desigualdade de renda entre negros e brancos.

Para investigar a existência de disparidade racial de riqueza em termos de nível, será utilizada a medida de riqueza proposta por Medeiros (2005). Peichl et al. (2010) propõem modificações na função matemática que define essa medida, principalmente com o objetivo de ajustá-la a necessidades de comparações internacionais. Nesse sentido, uma de suas principais preocupações é a de estabelecer uma função insensível à escala dos rendimentos (o que é fundamental para a comparabilidade entre medidas de riqueza para países com moedas e níveis de rendimento distintos) e também a conveniência de uma medida dotada de valor máximo (no caso, a unidade). Essas preocupações não são, contudo, relevantes para o presente trabalho, o que motiva a utilização da formulação proposta por Medeiros (2005), que é muito mais intuitiva.

\subsection{Forma e nível da distribuição de renda entre os grupos raciais}

O que aconteceria com a desigualdade de renda na população como um todo caso a diferença de nível entre os rendimentos de negros e de brancos se mantivesse, mas a 
distribuição entre os negros assumisse a mesma forma que a distribuição entre os brancos atualmente possui? Por outro lado, o que aconteceria com a desigualdade global se o nível da distribuição de renda entre os negros se igualasse ao nível da distribuição de renda entre os brancos mantendo-se inalterada, contudo, a forma das respectivas distribuições? E se tanto nível quanto forma fossem equiparados? Esses são cenários hipotéticos interessantes do ponto de vista interpretativo, pois representam situações-limite daquilo que podem ser processos reais de redução da desigualdade racial, especialmente quanto à correção da disparidade racial de riqueza. Para compreender isso, observe primeiro a forma e o nível das distribuições de renda dos grupos raciais.

A distribuição de renda dos brancos supera a distribuição dos negros em nível e difere desta em forma, sendo muito mais desigual. Para representar essas diferenças, utilizam-se as curvas de Lorenz, que constituem um dos recursos mais difundidos no estudo sobre desigualdade de rendimentos. As curvas de Lorenz dispõem frações acumuladas da população no eixo horizontal e frações acumuladas da renda total no eixo vertical. O Gráfico 4.1 mostra, simultaneamente, as curvas de Lorenz para negros e para brancos, calculadas separadamente para cada grupo.

Gráfico 4.1: Curvas de Lorenz para negros e brancos. Brasil, renda igual ou superior a um salário mínimo, 2010.

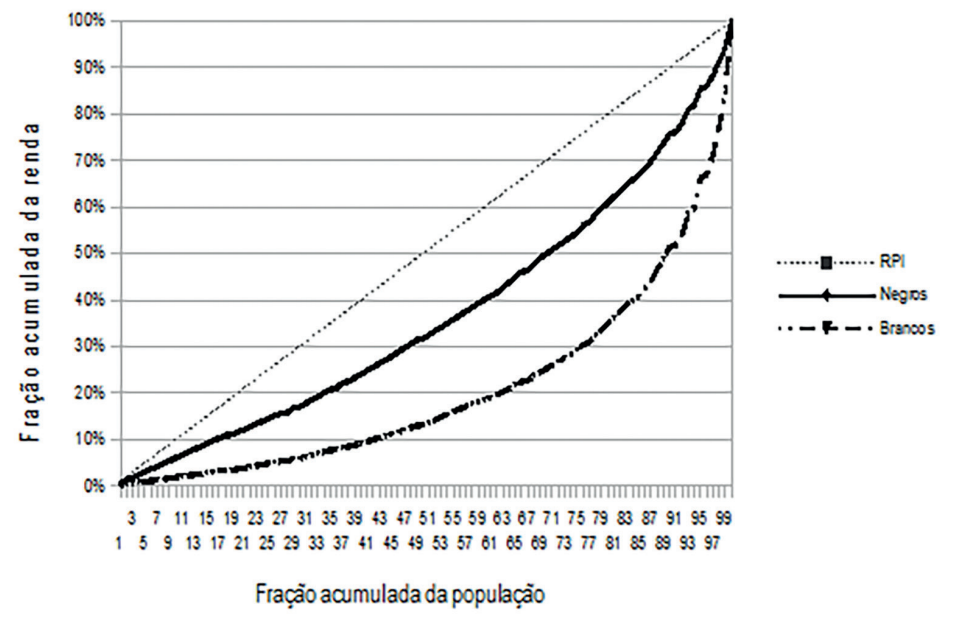

Fonte: IBGE - Censo Demográfico 2010 - Microdados. Elaboração própria. 
A melhor forma de compreender esse gráfico é partindo da situação de perfeita igualdade, representada pela Reta da Perfeita Igualdade, em pontilhado. Se a distribuição de renda em um grupo fosse perfeitamente igualitária, então, 20\% da sua população acumularia 20\% da renda do grupo, 40\% da população acumularia $40 \%$ da renda do grupo e assim sucessivamente, o que formaria uma reta. Por outro lado, quanto maior o arco da curva, maior a desigualdade de renda no grupo em questão. A curva se torna mais e mais côncava à medida que maiores parcelas da população mais pobre recebem uma menor proporção acumulada dos rendimentos totais. Observa-se assim a maior desigualdade de renda no interior do grupo dos brancos. Note, por exemplo, que, entre os negros, os 35\% mais pobres detêm 20\% da renda total do grupo. Já os 35\% mais pobres entre os brancos detêm apenas $8 \%$ da renda total desse grupo racial. Por outro lado, a fração dos $5 \%$ mais ricos entre os negros concentram 14\% do total de renda do grupo. Já entre os brancos, os mesmos 5\% mais ricos concentram 34\%.

O Coeficiente de Gini é uma medida estreitamente associada à Curva de Lorenz. Como foi visto, quanto mais côncava for a Curva de Lorenz, isto é, quanto maior for a sua distância em relação à reta da perfeita igualdade, maior a desigualdade na distribuição. O Coeficiente de Gini é uma função dessa distância. Se a Curva de Lorenz coincide com a reta da perfeita igualdade, então não haverá tal distância e o Coeficiente de Gini será igual a zero. Quanto mais a curva se afasta da reta, maior o Coeficiente de Gini se torna, até o limite de um. A Tabela 4.1, a seguir, dispõe o Coeficiente de Gini para a população total e para cada um dos grupos raciais: ${ }^{1}$

1 O uso do Coeficiente de Gini como medida de desigualdade é bastante difundido. É possível que o leitor confronte o valor aqui informado com valores informados por outras fontes. Antes de comparar esses valores e estranhar incompatibilidades, o leitor deve notar duas coisas. Primeiro: quais rendimentos estão sendo estudados. No presente caso, tratam-se dos rendimentos do trabalho principal. Por outro lado, boa parte das medidas de coeficientes de Gini divulgada ao público refere-se a rendimentos domiciliares per capita. Segundo: deve-se considerar a seleção da amostra em estudo. No presente caso, a diferença mais drástica é a exclusão de rendimentos inferiores a um salário mínimo. Essa exclusão certamente reduz a dispersão nos rendimentos e, portanto, as medidas de desigualdade. As restrições na idade para inclusão na amostra também têm um efeito de uniformização sobre os 
Tabela 4.1: Coeficiente de Gini para negros, brancos e população total. Brasil, renda igual ou superior a um salário mínimo, 2010.

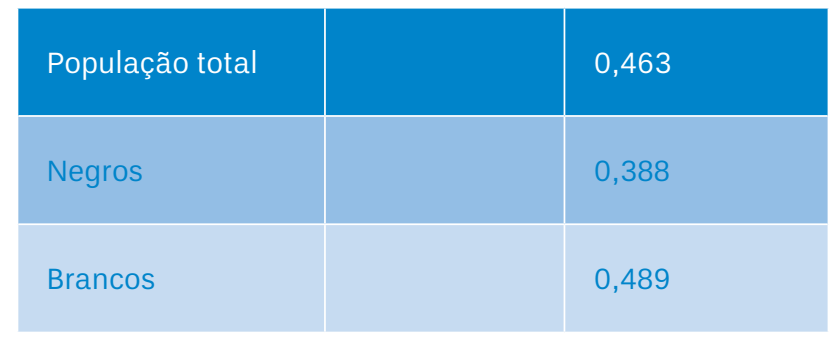

Fonte: IBGE - Censo Demográfico 2010 - Microdados. Elaboração própria.

A desigualdade entre os brancos é quase 0,10 ponto maior que a desigualdade entre os negros. O valor para a desigualdade total fica entre os dois valores, mas se aproxima mais do valor para a população branca. Tudo isso é fruto do fato de que, embora os brancos se concentrem nas posições mais elevadas da distribuição de renda, eles ainda são $40 \%$ entre os que têm renda em torno de um salário mínimo. Ao mesmo tempo, os brancos representam algo em torno de $80 \%$ dos $5 \%$ mais ricos. Em outras palavras, os brancos estão mais distribuídos que os negros por todos os percentis de renda, e concentram a maior parte da riqueza. Assim sendo, sua distribuição de renda assemelha-se mais, em forma, à distribuição da população total, e isso se reflete no Coeficiente de Gini.

Note-se que as curvas de Lorenz são insensíveis a variações na escala dos rendimentos. Por exemplo, se a renda de todas as pessoas brancas fosse multiplicada por 10, de modo que, ao longo de toda distribuição, os brancos recebessem rendimentos pelo menos 10 vezes superiores aos dos negros, a Curva de Lorenz, conforme apresentada acima, permaneceria inalterada. O nível de renda dos brancos seria maior que o atual, mas as proporções da renda total acumulada por cada

rendimentos, já que os valores de renda se dispersam de acordo com a idade. Utilizando os dados da PNAD 2012 sobre rendimentos do trabalho principal para todas as pessoas com dez anos ou mais de idade que estavam trabalhando, e sem a exclusão de rendimentos inferiores a um salário mínimo, obtém-se um Coeficiente de Gini, para a população total, no valor de 0,491. 
porção da população não mudariam. Nesse sentido, a Curva de Lorenz oferece uma representação para a forma da distribuição de rendimentos, mas ignora o seu nível.

Uma forma tradicional de se representar ao mesmo tempo, graficamente, forma e nível de distribuições de renda é a Curva de Lorenz Generalizada. Trata-se tão somente de uma modificação das curvas de Lorenz convencionais, onde se multiplicam todos os valores do eixo vertical pela renda média do respectivo grupo. No presente caso, o estudo da Curva de Lorenz Generalizava se torna ainda mais intuitivo se, no lugar da média, utilizarmos os totais de renda para cada grupo. Neste caso, em vez de frações da média dos rendimentos, o eixo vertical do gráfico passa a representar frações da renda total acumulada por cada grupo racial. Pense nesse total de rendimentos como o total de recursos de bem-estar disponível a cada grupo racial. As curvas mostram, então, como esse bem-estar é distribuído cumulativamente no interior dos respectivos grupos. A seguir, o Gráfico 4.2 mostra os resultados dessa operação. As cifras são, obviamente, muito altas e, por isso, os rendimentos são expostos em notação científica. De qualquer modo, o que importa é a comparação entre os grupos, e não os valores absolutos de rendimento.

Gráfico 4.2: Curvas de Lorenz generalizadas pelo total de rendimentos. Brasil, renda igual ou superior a um salário mínimo, 2010.

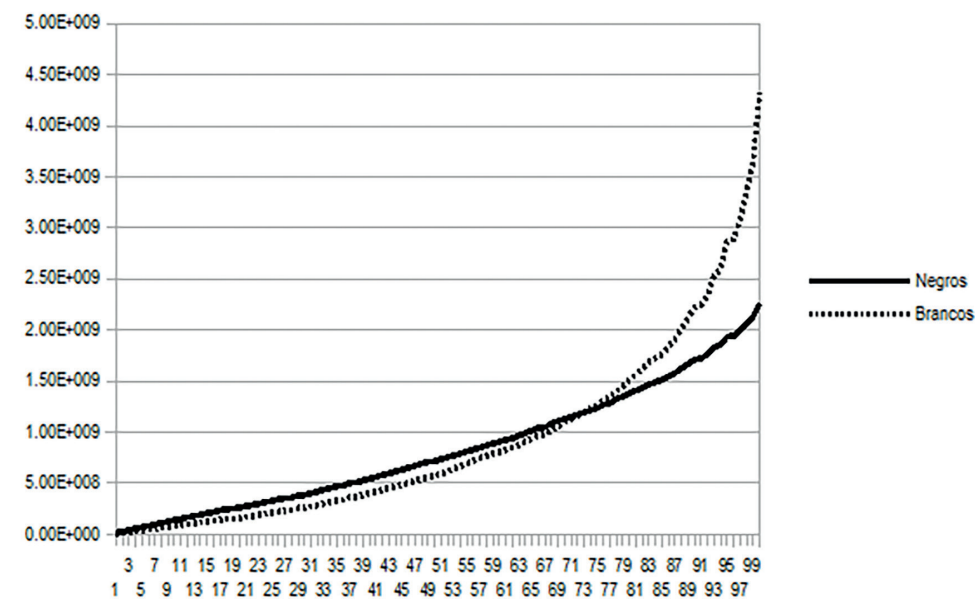

Fonte: IBGE - Censo Demográfico 2010 - Microdados. Elaboração própria. 
A melhor forma de compreender essas curvas é pensar nelas como uma mistura entre forma (desigualdade) e nível da distribuição de renda. O quanto uma curva se mantém acima ou abaixo da outra depende basicamente dos resultados dessa mistura até determinado quantil. $\mathrm{O}$ fato de a curva dos negros manter-se acima da curva dos brancos ao longo de boa parte de percentis tem a ver não com o nível da distribuição de renda dos negros (que é menor), mas sim com sua forma. Como a distribuição de renda entre os negros é menos desigual, as frações mais pobres acumulam uma porção maior da renda total do grupo. Já entre os brancos, essa fatia é comparativamente muito menor. A curva dos brancos ultrapassa a dos negros à altura do $73^{\circ}$ percentil. A essa altura, onde as curvas se cruzam, a população negra acumula 53\% da sua renda total, enquanto a população branca apenas $28 \%$. Em outras palavras, 28\% da renda total dos brancos equipara-se a 53\% da renda total dos negros. A partir daí, a curva dos brancos distancia-se rapidamente da curva dos negros, mostrando níveis de rendimento acumulado muito superiores.

Gráfico 4.3: Decomposição da Curva de Lorenz por grupos raciais.

Brasil, renda igual ou superior a um salário mínimo, 2010.

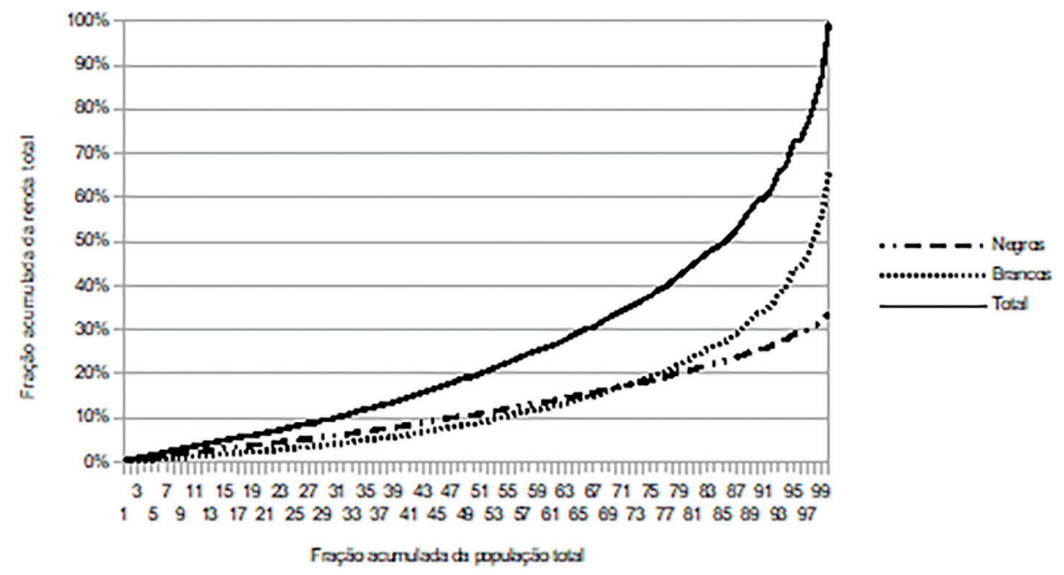

Fonte: IBGE - Censo Demográfico 2010 - Microdados. Elaboração própria.

Se as diferenças na distribuição de renda entre os grupos raciais são tanto de nível quanto de forma, é preciso levar isso em consideração no momento de 
relacionar a desigualdade entre os grupos raciais à desigualdade total. Essas diferenças de forma na desigualdade interna aos grupos implicam uma contribuição diferencial para a forma da desigualdade total. O Gráfico 4.3 ilustra essa relação. Ele traz a Curva de Lorenz para a população total e, sobrepostas a essa, curvas da contribuição de cada grupo racial para a proporção da renda total acumulada em cada percentil. Em outras palavras, em cada percentil, a Curva de Lorenz para a população total é decomposta em termos da contribuição de cada grupo racial.

Percebe-se nitidamente que a curva de contribuição dos brancos responde muito mais pela forma da distribuição total. A curva de contribuição dos negros é, por assim dizer, achatada, enquanto a curva de contribuição dos brancos acompanha muito proximamente a forma da Curva de Lorenz da população total. A distribuição dos brancos é um retrato mais próximo da desigualdade global, porque a desigualdade racial de renda manifesta-se pela pouca presença dos negros entre os mais ricos, o que distorce sua distribuição no sentido de uma maior igualdade diretamente relacionada ao menor nível de afluência econômica. O que se deduz disso é que a redução da desigualdade racial impactaria a desigualdade de renda global de maneiras muito diferentes, a depender de como se alterem o nível ou a forma da distribuição de renda dos negros. É possível fazer exercícios contrafatuais para explorar cenários hipotéticos dessa alteração. Para tanto, uma particular medida de desigualdade se mostra útil.

O Índice de Theil é uma medida sintética de desigualdade, como o coeficiente de Gini, embora não tenha a mesma associação com a Curva de Lorenz. Para compreendê-lo, é suficiente considerar que ele cresce à medida que os valores dos rendimentos em determinado grupo se dispersam em torno da média. Numa situação de completa igualdade, onde todas as pessoas recebem o mesmo rendimento, esse rendimento recebido por cada pessoa será, necessariamente, igual à média. Nessa situação, o Índice de Theil é igual a zero. À medida que os valores se dispersam em torno da média, o índice assume valores maiores. Diferentemente do Coeficiente de Gini, que varia apenas entre zero e um, o Índice de Theil pode crescer indefinidamente, embora valores superiores à unidade não sejam usuais. 
A Tabela 4.2 mostra o Índice de Theil para a população total e para cada um dos grupos raciais:

Tabela 4.2: Índices de Theil para negros e brancos. Brasil, renda igual ou superior a um salário mínimo, 2010.

\begin{tabular}{|l|l|l|}
\hline População Total & $\mathbf{0 , 5 1 0}$ \\
\hline Negros & 0,370 \\
\hline Brancos & 0,548 \\
\hline
\end{tabular}

Fonte: IBGE - Censo Demográfico 2010 - Microdados. Elaboração própria.

De acordo com o esperado, do mesmo modo que os coeficientes de Gini apresentados anteriormente, os índices de Theil mostram que a desigualdade é maior entre os brancos do que entre os negros, e que a magnitude da desigualdade geral está em um ponto intermediário entre essas duas, aproximando-se mais, contudo, da desigualdade no grupo dos brancos.

O primeiro passo para a implementação dos exercícios contrafatuais é decompor o Índice de Theil da população total em termos de contribuições dos grupos raciais. ${ }^{2}$ A ideia básica é decompor a desigualdade nos rendimentos da população em termos de duas fontes de variação: a desigualdade entre os grupos e a desigualdade

2 O campo de estudos sobre decomposição de medidas de desigualdade é bastante amplo. No presente estudo, interessa apenas a decomposição aditiva, o que exclui índices muito conhecidos, como o de Gini. Pyatt (1976) propõe interpretações para uma maneira possível de decompor aditivamente o Coeficiente de Gini. Contudo, aplicações desse procedimento não são usuais, já que um dos termos da decomposição (chamado de overlap e referente ao fato de que um grupo com menor renda média possui certos indivíduos com rendimento maior que indivíduos do grupo com maior renda média) dificilmente rende interpretações de valor substantivo. As medidas aditivamente decomponíveis mais conhecidas e empregadas são os índices de Theil, ou, de modo mais geral, a família de Medidas de Entropia Generalizada, da qual o Índice de Theil faz parte. Contudo, outro proeminente autor merece ser mencionado, embora tenha utilizado uma medida de desigualdade mais básica. No clássico Equality of educational opportunity, James Coleman (1966) emprega a decomposição aditiva da variância das notas dos estudantes em termos de: (i) variância dentro dos grupos (entre os alunos de uma mesma escola) e (ii) variância entre os grupos (entre as médias das escolas). 
dentro dos grupos. A contribuição da desigualdade interna aos grupos depende de duas coisas: o Índice de Theil do respectivo grupo (a forma da sua distribuição) e a fração da renda total acumulada por ele (o nível da sua distribuição). Se a desigualdade dentro do grupo é maior, sua contribuição também será maior, tudo mais constante. Se um grupo acumula uma fração maior dos rendimentos totais, sua contribuição para o índice também será maior. A contribuição do grupo obtém-se pelo produto entre a sua fração acumulada e o seu Índice de Theil. Para obter o índice total, soma-se às contribuições dos grupos o Índice de Theil correspondente à desigualdade entre as rendas médias (desigualdade entre os grupos). A Tabela 4.3 apresenta os resultados dessa decomposição. ${ }^{3}$

Tabela 4.3: Decomposição do Índice de Theil. Brasil, renda igual ou superior a um salário mínimo, 2010.

\begin{tabular}{|l|c|c|c|c|}
\hline \multicolumn{2}{|c|}{ Fonte de variação } & $\begin{array}{c}\text { Fração da } \\
\text { renda total }\end{array}$ & $\begin{array}{c}\text { Índice de } \\
\text { Theil }\end{array}$ & $\begin{array}{c}\text { Contribuição para } \\
\text { o Índice Total }\end{array}$ \\
\hline Interna aos Grupos & Brancos & 0.657 & 0.548 & $70.5 \%$ \\
\cline { 2 - 5 } & Negros & 0.343 & 0.370 & $24.9 \%$ \\
\hline Entre os Grupos & & - & 0.023 & $4.6 \%$ \\
\hline Total & - & $\mathbf{0 . 5 1 0}$ & $\mathbf{1 0 0 \%}$ \\
\hline
\end{tabular}

Fonte: IBGE - Censo Demográfico 2010 - Microdados. Elaboração própria.

Primeiramente, confirma-se a impressão de que a desigualdade interna ao grupo dos brancos é a que mais contribui para o índice geral de desigualdade. O grupo dos brancos responde por 70,54\% do índice total. Mais ainda, nota-se que isso se deve tanto à maior desigualdade interna ao grupo dos brancos quanto ao fato desse grupo acumular uma fração muito maior dos rendimentos totais. Em outras

3 A aplicação do Índice de Theil ora apresentada informa-se em um working paper entitulado The Young Person's Guide to the Theil Index: suggesting intuitive interpretations and exploring analytical applications, de Pedro Conceição e Pedro Ferreira (2000). 
palavras, a maior contribuição do grupo dos brancos para o padrão de desigualdade na população total se deve, por um lado, à forma dessa distribuição, ou seja, ao fato de ela ser muito mais desigual, e, por outro lado, ao seu nível. Quanto à desigualdade entre os grupos, nota-se que sua contribuição é bastante discreta: 4,6\% para o índice total. Para interpretar adequadamente esse fato é preciso considerar o que essa medida significa em termos de seu cômputo. Como já enfatizado, a contribuição da desigualdade entre os grupos para a desigualdade total depende basicamente da diferença entre as rendas médias de cada um deles. Portanto, é de se esperar que, no presente caso, a desigualdade entre os grupos contribua relativamente menos para a desigualdade total. Espera-se que a variação entre duas médias (rendas médias dos negros e dos brancos) em torno da média total seja menor que a variação dos rendimentos de todos os indivíduos de um grupo em torno da média desse grupo.

Assim, a diferença entre médias não é o modo mais importante pelo qual a desigualdade entre os grupos raciais contribui para a desigualdade total. Essa relação se estabelece principalmente pelo modo como a desigualdade entre os grupos associa-se a diferentes padrões de desigualdade dentro dos grupos, assim como à desproporção entre suas apropriações da renda total disponível na população. A muito maior contribuição da desigualdade interna ao grupo dos brancos está diretamente associada à concentração dos negros entre os estratos mais pobres, o que implica uma distribuição de renda muito menos desigual, assim como a apropriação de uma fração muito menor dos rendimentos totais disponíveis.

Agora, o que aconteceria então com a desigualdade de renda na população como um todo caso a diferença de nível entre os rendimentos de negros e de brancos se mantivesse, mas a distribuição entre os negros assumisse a mesma forma que a distribuição dos brancos atualmente possui? Esse cenário hipotético representa uma situação-limite para o caso de surgimento de mais pessoas negras ricas, graças, talvez, a eventuais políticas de ação afirmativa para carreiras de alto retorno financeiro. Formar-se-ia uma elite negra maior em proporção, tornando a distribuição de renda no interior do grupo mais desigual. Considere-se que, nesse cenário, 
a proporção da renda total apropriada por cada grupo permanecesse a mesma, ou seja, que não houvesse redução da desigualdade de nível entre os grupos. É um pouco estranho imaginar isso, já que o aumento do número de negros ricos elevaria o nível da distribuição como um todo, aproximando-o da dos brancos. Contudo, é possível imaginar a situação em que os brancos, de maneira geral, aumentariam seus níveis de rendimento de modo a compensar essa aproximação dos negros. Para essa situação, no limite, o grupo dos negros passaria a ter o mesmo Índice de Theil que o grupo dos brancos, mantendo, contudo, sua proporção original da renda total acumulada. A Tabela 4.4 mostra como isso afetaria a desigualdade global e a contribuição dos respectivos grupos. Nota-se que a desigualdade total aumentaria consideravelmente com o índice indo do original, 0,51, a mais de 0,57. A contribuição da desigualdade interna ao grupo dos negros, que era de aproximadamente $25 \%$, passaria a ser praticamente 33\%. A contribuição da desigualdade entre os grupos, que é a mesma em níveis absolutos, seria ligeiramente menor em termos relativos.

Tabela 4.4: Primeira simulação com o Índice de Theil. Brasil, renda igual ou superior a um salário mínimo, 2010.

\begin{tabular}{|l|c|c|c|c|}
\hline \multicolumn{2}{|c|}{ Fonte de variação } & $\begin{array}{c}\text { Fração da } \\
\text { renda total }\end{array}$ & $\begin{array}{c}\text { Índice } \\
\text { de Theil }\end{array}$ & $\begin{array}{c}\text { Contribuição para } \\
\text { o Índice Total }\end{array}$ \\
\hline & Brancos & 0.657 & 0.548 & $63.00 \%$ \\
\hline Interna aos grupos & Negros & 0.343 & 0.548 & $32.93 \%$ \\
\hline Entre os grupos & & - & 0.023 & $4.07 \%$ \\
\hline Total & - & $\mathbf{0 . 5 7 1}$ & $\mathbf{1 0 0 . 0 0 \%}$ \\
\hline
\end{tabular}

Fonte: IBGE - Censo Demográfico 2010 - Microdados. Elaboração própria.

Outro cenário interessante é aquele em que, com a forma da distribuição dos negros tornando-se como a dos brancos, desaparecesse a desigualdade de nível entre os grupos. Esse é o cenário mais natural de se imaginar no caso de aumento na 
proporção de negros relativamente ricos. À medida que a forma da distribuição de renda entre os negros se aproximaria daquela dos brancos, o grupo dos negros passaria a acumular proporções maiores da renda total disponível. No limite, o grupo acumularia uma fatia da renda total proporcional ao seu tamanho. Sendo que os negros perfazem $46 \%$ da população ora em estudo, considera-se, portanto, que essa seria a proporção da renda total acumulada por eles na situação de igualdade de nível entre os grupos. A Tabela 4.5, a seguir, mostra os detalhes da decomposição nesse cenário.

Tabela 4.5: Segunda simulação com o Índice de Theil. Brasil, renda igual ou superior a um salário mínimo, 2010.

\begin{tabular}{|c|c|c|c|c|}
\hline \multicolumn{2}{|c|}{ Fonte de variação } & $\begin{array}{l}\text { Fração da } \\
\text { renda total }\end{array}$ & $\begin{array}{l}\text { Índice } \\
\text { de Theil }\end{array}$ & $\begin{array}{l}\text { Contribuição para } \\
\text { o Índice Total }\end{array}$ \\
\hline \multirow{2}{*}{$\begin{array}{l}\text { Interna aos } \\
\text { grupos }\end{array}$} & Brancos & 0,54 & 0,548 & $54,0 \%$ \\
\hline & Negros & 0,46 & 0,548 & $46,0 \%$ \\
\hline \multicolumn{2}{|l|}{ Entre os grupos } & - & 0,000 & $0,0 \%$ \\
\hline \multicolumn{2}{|l|}{ Total } & - & 0,548 & $100,0 \%$ \\
\hline
\end{tabular}

Fonte: IBGE - Censo Demográfico 2010 - Microdados. Elaboração própria.

A desigualdade agora sobe de 0,51 para 0,54 , e não mais para 0,57. Como se nota, haveria ainda aumento na desigualdade total. A eliminação da desigualdade entre os grupos ameniza o incremento na desigualdade total, mas não chega, contudo, a compensá-lo. O resultado final continua sendo uma distribuição de renda mais desigual na população como um todo. Observe-se que o índice total é necessariamente igual ao índice de cada um dos grupos, que são agora equivalentes. Sendo os grupos agora igualmente desiguais, suas contribuições variam apenas de acordo com a fração da renda total acumulada por eles. 
O terceiro cenário a ser explorado corresponde à eliminação da desigualdade de nível sem alteração da diferença de forma entre as duas distribuições. Nesse caso, os negros passam a acumular uma fração da renda total semelhante àquela acumulada pelos brancos, não pelo crescimento de uma fração de negros ricos, mas pelo aumento da renda nas posições mais baixas e intermediárias da distribuição. O cenário faz sentido como limite para uma situação em que a população negra se torna desproporcionalmente beneficiada por uma elevação nos níveis de rendimento da população mais pobre e, mais ainda, pela redução dos níveis de desemprego e de inatividade. Nesse caso, estaria em jogo o aumento da massa de negros no mercado de trabalho recebendo salários de nível razoável. A desigualdade de renda média entre os grupos não estaria, de fato, desaparecendo, pois o aumento na proporção da renda acumulada pelo grupo seria acompanhado pelo aumento no tamanho do grupo. Em outras palavras, nessa situação, para acumular, enquanto grupo, uma proporção dos rendimentos totais equivalente ao rendimento dos brancos, o grupo teria que ter uma presença mais massiva no mercado de trabalho. Como a média é a divisão da renda total pelo número de pessoas com rendimentos, a renda média dos negros continuaria menor que a renda média dos brancos, mesmo os negros acumulando uma porção mais equânime da renda total disponível.

Considere-se que, nessa situação limite, a desigualdade entre os rendimentos médios de cada grupo se mantenha como a atualmente observada, e que as proporções da renda total acumulada por cada grupo se tornem as mesmas que as do exercício anterior: 54\% para os brancos e $46 \%$ para os negros. Note-se, contudo, que, nesse cenário, essas proporções não seriam equivalentes à proporção dos grupos na população. Os negros continuariam com uma proporção dos rendimentos inferior à sua proporção na população, pois, nesse caso, a aproximação entre os grupos estaria se dando também pelo aumento do quantitativo de negros trabalhando, a ponto de esse grupo acumular frações maiores da renda total disponível. A Tabela 4.6, a seguir, mostra a decomposição com esse cenário hipotético: 
Tabela 4.6: Terceira simulação com o Índice de Theil. Brasil, renda igual ou superior a um salário mínimo, 2010.

\begin{tabular}{lcccc}
\multicolumn{1}{c}{ Fonte de variação } & $\begin{array}{c}\text { Fração da } \\
\text { renda total }\end{array}$ & $\begin{array}{c}\text { Índice } \\
\text { de Thell }\end{array}$ & $\begin{array}{c}\text { Contribuição para o } \\
\text { Índice Total }\end{array}$ \\
\hline & Brancos & 0,54 & 0,548 & $60,5 \%$ \\
\hline Interna aos Grupos & Negros & 0,46 & 0,370 & $34,8 \%$ \\
\hline Entre os Grupos & - & 0,023 & $4,8 \%$ \\
\hline Total & - & 0,489 & $100,0 \%$
\end{tabular}

Fonte: IBGE - Censo Demográfico 2010 - Microdados. Elaboração própria.

Como se nota, esse é o único cenário em que há queda na desigualdade total. Esta cai em pouco mais de 2 pontos. A contribuição da desigualdade entre os grupos, que continua a mesma em termos absolutos, passa a pesar um pouco mais em termos relativos. São 4,8\% contra os 4,6\% na situação real. As contribuições dos grupos também mudam, passando a ser menos díspares.

Pelo conjunto das simulações, o que se nota é que a redução da desigualdade racial não necessariamente implica uma redução da desigualdade de renda na população como um todo. Os primeiros cenários refletem os resultados de ações que aumentam a representatividade dos negros entre os grupos mais ricos. Tais ações direcionadas poderiam reverter a desigualdade racial, mas aumentariam a desigualdade total. Esse aumento seria, contudo, suavizado no caso de redução ou do virtual desaparecimento da desigualdade de renda média entre os grupos raciais. Já o terceiro cenário representa uma situação limite do que poderia acontecer graças a processos de inclusão social, sobretudo acompanhados de uma política de valorização do salário mínimo. Por estar a população negra concentrada entre os mais pobres, ela seria desproporcionalmente beneficiada por essas mudanças. Nesse cenário, o que se observa é uma queda na desigualdade total sem que a desigualdade de nível entre negros e brancos seja reduzida. 


\subsection{Composição e nível da disparidade racial de riqueza}

Nesta seção, aborda-se a desigualdade racial existente dentro do grupo dos ricos. O fato de que os negros estão pouco representados no grupo dos ricos já foi amplamente documentado. Agora, interessa investigar a distribuição de renda entre negros e brancos ricos, sendo que a hipótese de trabalho é a de que os negros ricos são menos afluentes que os seus pares brancos. Como já dito, define-se aqui como ricas as pessoas no último percentil da distribuição de renda ou, em português claro, o grupo composto pelo $1 \%$ de pessoas mais ricas, em termos de renda do trabalho principal, da população. É plausível esperar que o padrão de concentração do negro nas posições de menor renda, observado na população como um todo, se reproduza dentro do próprio grupo das pessoas relativamente mais ricas.

Para investigar isso, é adequado utilizar a medida de riqueza proposta por Medeiros (2005). A medida é elaborada com base na família FGT de medidas de pobreza e constitui uma espécie de média dos hiatos de riqueza, isto é, das distâncias entre determinada renda individual e a linha de riqueza que, no presente caso, é definida como R\$11.000,00. Esse hiato é dividido pelo valor da própria linha de riqueza, o que é uma espécie de normalização que torna os valores em questão mais tratáveis em termos de escala. Existindo $n$ pessoas ricas numa população, $n$ valores (correspondentes aos hiatos de riqueza normalizados de cada indivíduo) são somados e, então, divididos por $n$, ou seja, pelo número de ricos. Além disso, os hiatos de riqueza podem ser elevados a diferentes potências (usualmente zero, um ou dois), o que fará com que a medida final represente coisas diferentes. Quando se escolhe a potência zero, a medida representa a proporção de ricos. Quando se escolhe a potência igual à unidade, o resultado é uma medida que representa o volume dos rendimentos acima da linha de riqueza ou, em outras palavras, o quanto os ricos são ricos. Quando se escolhe potências maiores que a unidade, os valores passam a ganhar maior peso à medida que se afastam da linha de riqueza. Sendo assim, a medida resultante passa a trazer informações também sobre a desigualdade de renda entre os ricos, uma vez que rendas mais altas possuem maior 
peso, ricos muito ricos contribuem desproporcionalmente para a medida. Esse efeito é tanto maior quanto maior o valor adotado para a potência. ${ }^{4}$

Outra característica importante da medida proposta por Medeiros (2005) é que ela pode ser decomposta em termos das contribuições de cada grupo racial. Essa propriedade, somada às características descritas anteriormente, permite um exercício capaz de testar a hipótese de que os brancos ricos são mais ricos que os negros ricos. Uma vez que a escolha de potências maiores na definição da medida implica dar maior peso para rendas muito altas, o exercício consiste em decompor a medida entre negros e brancos para diferentes valores dessa potência que, seguindo a convenção, será chamada de alfa. Se está correta a hipótese de que os brancos ricos são mais ricos que os negros ricos, a contribuição do grupo dos negros deve diminuir à medida que se adote valores maiores de alfa. Em outras palavras, quanto mais a medida é sensível a rendas muito elevadas, maior deve ser a contribuição dos brancos para a medida total e menor a contribuição dos negros. A Tabela 4.7 apresenta o resultado desse exercício.

Tabela 4.7: Contribuição dos grupos raciais para a Medida FGT Invertida de Medeiros.

\begin{tabular}{|c|c|c|c|c|c|}
\hline & Alfa $=0$ & Alfa=1 & Alfa $=2$ & Alfa $=3$ & Alfa $=4$ \\
\hline Negros & $16,1 \%$ & $15,8 \%$ & $13,7 \%$ & $8,8 \%$ & $5,1 \%$ \\
\hline Brancos & $83,9 \%$ & $84,2 \%$ & $86,3 \%$ & $91,2 \%$ & $94,9 \%$ \\
\hline Total & $100,0 \%$ & $100,0 \%$ & $100,0 \%$ & $100,0 \%$ & $100,0 \%$ \\
\hline
\end{tabular}

Fonte: IBGE - Censo Demográfico 2010 - Microdados. Elaboração própria.

4 Na literatura especializada, essa discussão geralmente é conduzida em termos de "transferências" de renda. Naquele contexto de discussão, o que acaba de ser exposto equivale a afirmar que a medida de riqueza com potências superiores à unidade é sensível a transferências de renda dos ricos menos ricos para os ricos mais ricos, ou seja, a medida de riqueza cresce sempre que uma quantidade " $x$ " de renda é transferida de um rico mais modesto para um rico mais rico. No presente caso, a apresentação da medida é conduzida mais no espírito da aplicação particular que aqui lhe será dada, por isso não se faz menção à ideia de transferências de renda especificamente. 
Quando o valor de alfa é igual a zero, a decomposição da medida de riqueza indica a proporção do respectivo grupo entre os ricos, o que significa que aproximadamente $16 \%$ dos ricos são negros. À medida que os valores de riqueza são considerados (alfa igual a um) e que pesos progressivamente maiores são dados a rendas muitos elevadas (alfa maior que um), a contribuição dos negros para a medida total de riqueza se reduz consistentemente. Em outras palavras, se confirma a hipótese de que os brancos ricos são mais ricos que os negros ricos.

\subsection{Conclusão}

Neste capítulo, não apenas quantificou-se a sub-representação dos negros no grupo dos ricos como observou-se a relação entre essa sub-representação e a desigualdade de renda em geral. Além disso, identificou-se a desigualdade existente entre negros e brancos no interior do grupo dos ricos. Observou-se que a desigualdade entre negros e brancos está associada ao padrão de desigualdade de renda em geral na sociedade brasileira. Quanto a esse aspecto, uma das conclusões mais importantes é a de que essa contribuição da desigualdade entre negros e brancos para a desigualdade de renda em geral não deve ser avaliada apenas pela diferença de renda média entre os grupos raciais. Na verdade, a pouca participação dos negros na composição dos grupos mais ricos torna sua distribuição de renda muito diferente da distribuição de renda dos brancos não apenas em nível, mas também em forma. A população branca acumula uma porção substancialmente maior dos rendimentos totais disponíveis, e essa porção se distribui de forma acentuadamente desigual no interior do grupo. Com isso, a forma da distribuição de renda dos brancos está muito mais fortemente associada à forma da distribuição de renda total.

Com base na decomposição do Índice de Theil, notou-se que a redução da desigualdade racial de renda pode relacionar-se de maneiras muito distintas à desigualdade total. Mudanças na base da distribuição ao atingirem desproporcionalmente a população negra, reduzindo a desigualdade da fração acumulada 
dos rendimentos totais, mas não alterando a desigualdade racial de renda média, estariam associadas à redução da desigualdade global medida pelo Índice de Theil. Essa redução seria, contudo, sensivelmente reduzida pela permanência da desigualdade de renda média entre os grupos raciais. Por outro lado, o aumento da representatividade dos negros no grupo dos ricos implicaria um aumento na desigualdade total, mesmo esse aumento sendo amenizado pelo virtual desaparecimento da desigualdade entre grupos raciais. Assim, a correção da disparidade racial de riqueza não necessariamente anda em conjunto com a correção dos níveis globais de desigualdade de renda no Brasil.

Por fim, por meio da decomposição da medida de riqueza proposta por Medeiros (2005), verificou-se a existência de desigualdade racial dos níveis de riqueza, sendo os negros ricos relativamente menos endinheirados que os brancos ricos. É de se acreditar que estudos baseados em medidas de riqueza total encontrariam um padrão ainda mais agravado de desigualdade de riqueza, já que a transmissão de patrimônio por meio da herança certamente pesa mais a favor da população branca, dada a dimensão histórica da desigualdade racial. 